\title{
Exploring Route Choice Behaviours Accommodating Stochastic Choice Set Generations
}

\author{
Shin-Hyung Cho $\mathbb{D i D}^{1}$ and Seung-Young Kho $\mathbb{D}^{2}$ \\ ${ }^{1}$ School of Civil and Environmental Engineering, Georgia Institute of Technology, Atlanta, GA 30324, USA \\ ${ }^{2}$ Department of Civil and Environmental Engineering and Institute of Construction and Environmental Engineering, \\ Seoul National University, Seoul 08826, Republic of Korea \\ Correspondence should be addressed to Seung-Young Kho; sykho@snu.ac.kr
}

Received 14 January 2021; Revised 27 February 2021; Accepted 5 March 2021; Published 9 April 2021

Academic Editor: Young-Jae Lee

Copyright (c) 2021 Shin-Hyung Cho and Seung-Young Kho. This is an open access article distributed under the Creative Commons Attribution License, which permits unrestricted use, distribution, and reproduction in any medium, provided the original work is properly cited.

\begin{abstract}
Modelling route choice behaviours are essential in traffic operation and transportation planning. Many studies have focused on route choice behaviour using the stochastic model, and they have tried to construct the heterogeneous route choice model with various types of data. This study aims to develop the route choice model incorporating travellers' heterogeneity according to the stochastic route choice set. The model is evaluated from the empirical travel data based on a radio frequency identification device (RFID) called dedicated short-range communication (DSRC). The reliability level is defined to explore the travellers' heterogeneity in the choice set generation model. The heterogeneous $K$-reliable shortest path- (HK $\alpha$ RSP-) based route choice model is established to incorporate travellers' heterogeneity in route choice behaviour. The model parameters are estimated for the mixed path-size correction logit (MPSCL) model, considering the overlapping paths and the heterogeneous behaviour in the route choice model. The different behaviours concerning the chosen routes are analysed to interpret the route choice behaviour from revealed preference data by comparing the different coefficients' magnitude. There are model validation processes to confirm the prediction accuracy according to travel distance. This study discusses the policy implication to introduce the traveller specified route travel guidance system.
\end{abstract}

\section{Introduction}

Many studies have focused on the modelling behaviours of choosing routes using mathematical and empirical solutions. They have used various stochastic models to provide mathematical approaches for searching the available paths and choosing the most feasible routes [1-4]. Also, transportation researchers have attempted to formulate the route choice behaviours using empirical data. Recently, the development of intelligent transportation system (ITS), such as the vehicle detection system (VDS), automatic video system (AVS), closed-circuit television (CCTV), and variable message sign (VMS), has made it possible to collect and process the various data. These various types of travel information provide drivers' judgement about alternative routes [5].
Nevertheless, many travellers usually acquire limited information from experienced travel time [6]. The enormous amounts of data have allowed researchers to analyse travel behaviours and consider mathematical solutions. The process of generating a set of routes has been constructed using the travellers' cognitive process in choosing a route, and a reasonable number of routes have been derived from increasing the accuracy of the modelling process [7]. Furthermore, the researcher's interest in travel time reliability has increased during the last decades. The travel time reliability problem has required consideration of individuals' perceptions of the uncertainty of the travel time. The travel time perceived by an individual has been defined as a cumulative distribution function based on travellers' experiences [8, 9]. The concepts of perceived travel time and travel time 
reliability have been widely used to evaluate the traffic states in transportation operation.

Each traveller has a perceived travel time for a specific origin and destination (OD) pair to set up the travel time with travel time uncertainty when they start to travel. Even though there are several effective routes, travellers choose another route due to their travel experience. The process of generating a choice set involves modelling the cognitive process incorporating traveller's heterogeneity. The previous models based on rationality are somewhat limited in their ability to explain irrational choice behaviours. This problem results from the limited information about alternative routes. Many studies have recently explored these personal characteristics in the models, e.g., prospect theory, bounded rationality, and choice inertia. The route choice behaviour modelling should incorporate travellers' heterogeneity in the choice set generation and the route choice model. This study aims to construct the route choice model accommodating heterogeneous route choice behaviour for travel time reliability. The route choice model is developed through the heterogeneous $K$ - $\alpha$-reliable shortest path searching (HK $\alpha$ RSP) method using the reliability level derived by comparing the travel time budget (TTB) of the network of the individuals. Section 2 of this study reviews the choice set generation model and the route choice model comparing travel time reliability studies. In Section 3, the definitions of the terms are presented to establish the models. Section 4 introduces the methodology of determining the size of the choice set and the modelling of route choice behaviour which is developed using the concept of travel time reliability. An empirical analysis is conducted in Section 5 to estimate the route choice behaviour using processed travel data. Section 6 is the conclusion, which summarises the results of this study and discusses future research.

\section{Literature Review}

The traditional $K$ shortest paths were modelled to determine the shortest paths concerning the travel time, assuming the determined link travel time. However, link travel times in the network have consistently been observed to have stochastic characteristics recognised by travellers. Several methodologies have been proposed to measure travel time reliability, e.g., the probability of on-time arrival, the TTB, $\alpha$-reliable mean-excess travel time, and $\alpha$-reliable travel time for generating the route choice set [10]. Among these methodologies, the on-time arrival probability was applied to the route choice model. The probability distribution function enabled calculating the probability of occurrence for each path, and it generated $K$ paths according to their probabilities [11]. Mathematical modelling has been introduced to determine the optimal path from the sum of the distribution probabilities of the link travel time with the TTB $[12,13]$. Researchers have employed the label-correcting algorithm to analyse the time-dependent problem and search for reliable paths [14]. The deviation-based path set generation models have defined the distribution of link travel time as normal distribution and constructed the stochastic travel time between the OD pairs to compare the network's reliable paths.
These studies made it possible to remove nondominant paths and derive dominant paths through the various constraints $[15,16]$. Other studies derived a user equilibrium model by dividing the travel time variation into predictable and unpredictable travel times in the route choice process using the $\alpha$-reliable, mean-excess approach $[17,18]$. A route choice model was constructed which reflected risk-aversion characteristics by generating the probability using the TTB $[19,20]$. The other stochastic travel time-based models employed the TTB for travel time reliability to reflect individuals' heterogeneous risk-averse characteristics [21, 22]. The $\alpha$-reliable travel time was used to determine the optimal path based on travellers' risk preference using the TTB. The models classified individual risk preference levels into riskseeking, risk-neutral, and risk-averse travellers to derive the optimal paths for each scenario $[16,23]$. There was other research dealing with the system optimum model reflecting the fuzzy network theory. Research has considered the perceived travel time and risk-taking properties in traffic assignment problem by incorporating fuzzy utility theorem. They discussed the differences between conventional and fuzzy network theory-based equilibrium model [24-29].

Numerous studies have been conducted to reflect the individual's choice behaviour in the model. McFadden (1973) developed the multinomial logit (MNL) model, which is a general form of the random utility-based choice model [30]. In transportation demand analysis, the MNL model has been applied at the mode choice stage before using the route choice model. The probit model and the MNL model also were used in stochastic or probabilistic assignment models $[31,32]$. Many researchers have used explanatory variables to make the models more feasible, such as landmark dummy, percentage of the major road, percentage of uninterrupted flow, and delay percentage [1,3,33-35]. The MNL model had some drawbacks in the route choice model, i.e., (1) it does not consider the identification of an individual traveller's choice set, (2) it does not reflect the overlapping links in routes, and (3) it does not consider travellers' heterogeneity in choice behaviour. Several models have been proposed to improve the MNL model, including extended logit models to overcome overlapping links among routes. These models were composed of a deterministic term and a random error term that includes the additional overlapping term in the utility function. A modified MNL model, called the C-logit model, was proposed by subtracting the utility function's commonality [5]. Researchers have developed the implicit availability/perception (IAP) logit model by aggregating the path generation model and the route choice model using travellers' perceptions of routes [36]. The most considered route choice model to overcome the overlapping problem was the path-size logit model (PSL). The PSL model was introduced to modify the MNL model and considered the degree of overlapping of the routes in the MNL model [37-39]. The other researchers also proposed an improved PSL model, known as the path-size correction logit model (PSCL), by suggesting detailed and systematic derivations of the assumption for correcting the path-size factor [35]. There were other types of models based on the generalised extreme value (GEV) theory that considers the hierarchical 
structure for choices to capture the error component of overlapping links. Such models included the paired combinational logit (PCL) model [40, 41], the cross nested logit (CNL) model [34, 41, 42], the generalised nested logit (GNL) model [34, 43, 44], and the mixed multinomial logit (MMNL) model $[45,46]$ summarised in Table 1.

Since individual travellers have different travel experiences, they have different characteristics in determining choice sets and route choice behaviours. This study contributes a new approach for the generation of choice sets that incorporate individual travel behaviours and uses actual travel data to validate the choice behaviour. Significant differences compare the shortest path problem by perceived travel time from the previous research $[16,29]$. The different methodologies of choice set generation are compared to improve the accuracy of route choice models, i.e., the $k$ shortest paths-based choice model (KSP), the $k$ reliable shortest paths-based choice model (K $\alpha \mathrm{RSP})$, and the heterogeneous $k$ reliable shortest paths-based choice model (HK $\alpha \mathrm{RSP})$. The route choice models are used to compare the accuracy of choice probability according to the choice set generation methodologies from various choice models, i.e., MNL, PSL, PSCL, CNL, PCL, and MMNL models. The route choice model makes it possible to determine whether the choice set generation models are well-formulated.

\section{Measuring of Individual Travel Time Reliability}

3.1. Travel Time Budget (TTB). Travel time reliability is generated from the travel experience of individual travellers in specific OD pairs. It defines the distribution function of perceived travel time to obtain the probability of on-time arrival. The TTB is introduced to identify the risk preferences from the distribution as the value determined by the confidence level. The TTB has been defined the minimum total travel time threshold satisfied the reliability requirement with constraints, concerning the percentile of total travel time distribution specified by decision-makers using the confidence level, $\alpha$. The meaning of this definition is interpreted as the value derived from the distribution of travel time by using the predetermined confidence level $[9,47]$. Based on actual travel data and previous research, a lognormal distribution, a nonnegative and asymmetrical distribution, represents the stochastic travel time $[16,47]$. Therefore, the travel time distributions for OD pairs are assumed to follow a lognormal distribution, lognormal $(\mu, \sigma)$, represented to the probability density function $(\mathrm{PDF})$ and cumulative distribution function $(\mathrm{CDF})$. In this study, TTB means that travellers plan for the travel time before departure to achieve their requirement of travel time reliability, which is expressed by the distribution of travel time experienced in the network for the confidence level, $\alpha$, and the reliability level, $\alpha_{l}$. There are three kinds of TTBs, i.e., TTB in the network, TTB of route $k$, and TTB for an individual. The TTB is required to achieve an $\alpha$ confidence level in the network from the origin, $i$, to the destination, $j$. The TTB in the network is $\operatorname{TTB}_{T^{i j}}(\alpha)$ in equation
(1). TTB of the $\mathrm{k}^{\text {th }}$ path required achieving the $\alpha$ confidence level from the origin, $i$, to the destination, $j$. The TTB of route $k$ in the network is $\operatorname{TTB}_{T^{i j}}(\alpha)$ in equation (2). The TTB required to achieve the $\alpha$ confidence level for individual $l$ from the origin node $i$ to the destination node $j$. The TTB for individuals is $\operatorname{TTB}_{T^{i j l}}(\alpha)$ in equation (3):

$$
\begin{aligned}
& \operatorname{TTB}_{T^{i j}}(\alpha)=\exp \left(\mu^{i j}+\Phi_{T^{i j}}^{-1}(\alpha) \times \sigma^{i j}\right), \\
& \operatorname{TTB}_{T_{k}^{i j}}(\alpha)=\exp \left(\mu_{k}^{i j}+\Phi_{T_{k}^{i j}}^{-1}(\alpha) \times \sigma_{k}^{i j}\right), \\
& \operatorname{TTB}_{T^{i j l}}(\alpha)=\exp \left(\mu^{i j l}+\Phi_{T^{i j l}}^{-1}(\alpha) \times \sigma^{i j l}\right),
\end{aligned}
$$

where $i$ is the origin, $j$ is the destination, $k$ is the order of the $\alpha$-reliable path or the predetermined number of the route choice set, $l$ is the individual traveler, $\alpha$ is the confidence level (i.e., on-time arrival probability), $\mu^{i j}$ is the mean of the travel time distribution from the origin, $i$, to the destination, $j, \mu_{k}^{i j}$ is the mean of the travel time distribution of the $k^{\text {th }} \alpha$-reliable path from the origin, $i$, to the destination, $j, \mu^{i j l}$ is the perceived mean of travel time distribution for individual, $l$, from the origin, $i$, to the destination, $j, \sigma^{i j}$ is the standard deviation of travel time distribution from the origin, $i$ to the destination, $j, \sigma_{k}^{i j}$ is the standard deviation of the travel time distribution of the $k^{\text {th }} \alpha$-reliable path from the origin, $i$, to the destination, $j$, and $\sigma^{i j l}$ is the perceived standard deviation of the travel time distribution for individual, $l$, from the origin, $i$, to the destination, $j$.

3.2. Risk Preferences. The TTB has a structure combined with the predictable travel time in the travel time distribution. Travellers accept the predictable risk from their experiences to meet the predetermined travel time, which is defined as the TTB in the OD pair. Individual travellers set up a TTB for a specific OD pair using the perceived travel time based on their experience. The distribution of perceived travel time is expressed more clearly as individual travellers accumulated travel time for a specific OD pair. The travel time distribution in the network causes individual travellers to incur late arrivals because the distribution of the individual travel time is different from the distribution of the travel time determined by the network.

Reliability level $\left(\alpha_{l}\right)$ means that individuals determine the value of the probability of on-time arrival by cumulative distribution for a specific OD pair in the network based on repeated travels. When the TTB of an individual at the confidence level $\alpha$ has the same TTB of the network for a specific OD pair, the TTB represents the reliability level, $\alpha_{l}$ on the cumulative distribution of the network. The reliability level, $\alpha$, is expressed as the on-time arrival probability for an individual's perceived TTB from the travel time distribution in this study. Risk preference is defined that the travellers have the characteristics of risk-taking for travel failure or delay due to travel time reliability. Since individual travellers have different risk preferences based on their travel experiences for each specific OD pair $(i, j)$, the reliability level, $\alpha_{l}$, are determined individual risk preference. The 
TABLE 1: Summary of route choice models.

\begin{tabular}{|c|c|c|c|c|}
\hline \multicolumn{2}{|c|}{ Contents } & Model & Description & Study \\
\hline \multirow{4}{*}{ MNL } & $\begin{array}{c}\text { MNL } \\
\text { (multinomial } \\
\text { logit) }\end{array}$ & $P\left(r \mid Q_{d}\right)=\left(e^{V_{r}} / \sum_{r^{\prime} \in Q_{d}} e^{V_{r^{\prime}}}\right)$ & - & $\begin{array}{c}\text { Dial [1], Fisk [3], } \\
\text { Bekhor et al. [33], } \\
\text { Prato and Bekhor } \\
\end{array}$ \\
\hline & C-logit & 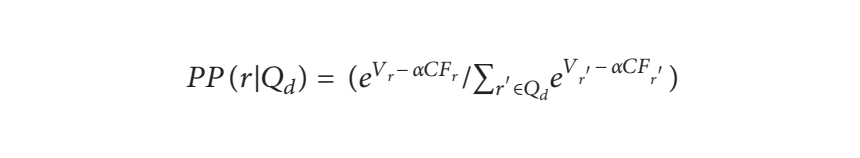 & $\begin{array}{l}\text { Subtracting } \\
\text { commonality factor }\end{array}$ & $\begin{array}{c}\text { Cascetta et al. [36], } \\
\text { schussler and } \\
\text { Axhausen [5], } \\
\text { zhou et al. [18] }\end{array}$ \\
\hline & $\begin{array}{l}\text { PSL (path-size } \\
\text { logit) }\end{array}$ & $P\left(r \mid Q_{d}\right)=\left(e^{V_{r}+\beta_{r} \ln \left(\mathrm{PS}_{r}\right)} / \sum_{r^{\prime} \in Q_{d}} e^{V_{r^{\prime}}+\beta_{r} \ln \left(\mathrm{PS}_{r^{\prime}}\right)}\right)$ & $\begin{array}{l}\text { Adding } \ln (\text { size }) \\
\quad \text { (path size) }\end{array}$ & $\begin{array}{l}\text { Frejinger et al. } \\
\text { [38], schussler and } \\
\text { Axhausen [5], Li } \\
\text { et al. [39] }\end{array}$ \\
\hline & $\begin{array}{l}\text { PSCL (path-size } \\
\text { correction logit) }\end{array}$ & 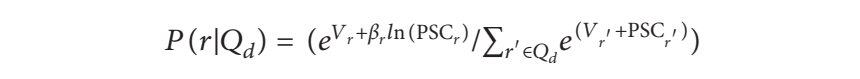 & $\begin{array}{l}\text { Adding PSC (path } \\
\text { size correction) }\end{array}$ & Bovy et al.(2008) \\
\hline \multirow{3}{*}{ GEV } & $\begin{array}{l}\text { PCL (paired- } \\
\text { combinational } \\
\text { logit) }\end{array}$ & $P\left(r \mid Q_{d}\right)=e^{\left(\mu V_{r} / 1-\sigma_{r}\right)} / \sum_{r^{\prime} \in Q_{d}} e^{\left(\mu V_{r^{\prime}} / 1-\sigma_{r^{\prime}}\right)}$ & $\begin{array}{c}\text { Multiplications of } \\
\text { unobserved } \\
\text { probability }\left(P_{i j}\right)\end{array}$ & $\begin{array}{l}\text { Bliemer and Bovy } \\
\text { [35] }\end{array}$ \\
\hline & $\begin{array}{l}\text { CNL (cross- } \\
\text { nested logit) }\end{array}$ & 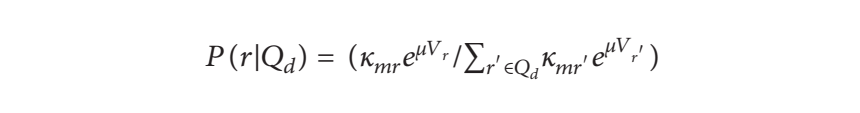 & $\begin{array}{l}\text { Multiplications of } \\
\text { Marginal(nested) } \\
\text { probability }\end{array}$ & $\begin{array}{l}\text { Prato and bekhor } \\
\text { [34], bliemer and } \\
\text { Bovy [35] }\end{array}$ \\
\hline & $\begin{array}{c}\text { GNL } \\
\text { (generalized } \\
\text { nested logit) }\end{array}$ & $P\left(r \mid Q_{d}\right)=\left(\alpha_{m r} e^{\mu V_{r}} / \sum_{r^{\prime} \in Q_{d}} \alpha_{m r^{\prime}} e^{e^{\mu V r^{\prime}}}\right)$ & $\begin{array}{c}\text { Including the } \\
\text { allocation } \\
\text { parameter }\left(m, \alpha_{n m}\right)\end{array}$ & $\begin{array}{l}\text { Prato and bekhor } \\
\text { [34], wen and } \\
\text { Koppelman [44] }\end{array}$ \\
\hline \multirow[b]{2}{*}{ MNW } & C-weibit & $P_{h}^{r s}\left(c^{r s}\right)=\left(e^{-\theta\left(c_{h}^{r s}+c f_{h}^{r s}\right)} / \sum_{l \in c^{r s}} e^{-\theta\left(c_{l}^{r s}+c f_{l}^{r s}\right)}\right)$ & \multirow{2}{*}{$\begin{array}{l}\text { Weibull distribution } \\
\text { based model (open } \\
\text { form) }\end{array}$} & Xu et al. [47] \\
\hline & $\begin{array}{l}\text { PSW (path-size } \\
\text { weibit) }\end{array}$ & $P_{i k}=\left(\left(c_{k}^{i}-\xi_{i}^{0}\right)^{-\beta_{i}} / \sum_{s \in K_{i}}\left(c_{k}^{i}-\xi_{i}^{0}\right)^{-\beta_{i}}\right)$ & & $\begin{array}{l}\text { Castillo et al. [52], } \\
\text { kitthamkesorn and } \\
\text { Chen [53] }\end{array}$ \\
\hline $\begin{array}{l}\text { Mixed } \\
\text { logit }\end{array}$ & $\begin{array}{c}\text { MMNL (mixed } \\
\text { multinomial } \\
\text { logit) }\end{array}$ & $P_{k}=\Lambda(k \mid \zeta)=\left(\exp \left(\mu\left(X_{k} \beta\right)+F_{k} T \zeta\right) / \sum_{r^{\prime} \in Q_{d}} \exp \left(\mu\left(X_{r^{\prime}} \beta\right)+F_{r^{\prime}} T \zeta\right)\right)$ & $\begin{array}{l}\text { Factor analytic } \\
\text { specification }\end{array}$ & $\begin{array}{l}\text { Ramming [51], } \\
\text { Prato and Bekhor } \\
\text { [34], Alizadeh et al. } \\
\text { [54], Lee et al. [55] }\end{array}$ \\
\hline
\end{tabular}

characteristics of individual travellers were categorised, as shown below [16]:

$$
\begin{aligned}
& \alpha_{l}>0.5, \text { risk-averse for on-time arrival } \\
& \alpha_{l}=0.5, \text { risk-neutral for on-time arrival } \\
& \alpha_{l}<0.5, \text { risk-seeking for on-time arrival }
\end{aligned}
$$

Risk preference is an essential factor in the choice set generation model. The process of choice set generation modelling is formulated using the reliability level, $\alpha_{l}$, which is referred to as risk preference. The reliability level, $\alpha_{l}$, is determined according to the difference between the individual's perceived travel time and the travel time provided by the network, so a difference occurred in generating the choice set. This analysis develops a route choice model that reflected travellers' behaviour according to whether they were risk-seeking or risk-averse in Figure 1. When the TTB for an individual is derived from the confidence level, $\alpha$, according to the mean and standard deviation in the travel time distribution, it is possible to compare the TTB for the individual and the network confidence level, $\alpha$. In other words, when the travel time experienced by an individual is less than the travel time in the network, the traveller would be concerned about late arrival based on the perceived travel time, in case of which it is defined as the risk-seeking characteristic. However, individual travellers' experiences indicate that they have more travel time than the network's travel time because they have experienced more travel time for the specific OD pair $(i, j)$. Risk preference makes travellers calculate the TTB to arrive on time, which is a characteristic of risk-averse travellers.

\section{Model Specifications}

4.1. Route Choice Behaviour. The travel behaviour models have developed the following structure by dividing the choice set generation and route choice model. Researchers have tried to construct the modelling framework of route choice behaviour [7, 46]. The model is constructed to determine the size of the consideration set and individual choice set. Consideration choice set is derived by the number of experienced routes using the observed data from the universal set occurring in the network for a specific OD pair. A modelling process also includes a different choice set for individuals using TTB and risk preference in the individual choice set generation. The route choice model using the individual choice set is derived from the collective individual travel data. The individual choice set is a set of routes for incorporating traveller's heterogeneity. It is 

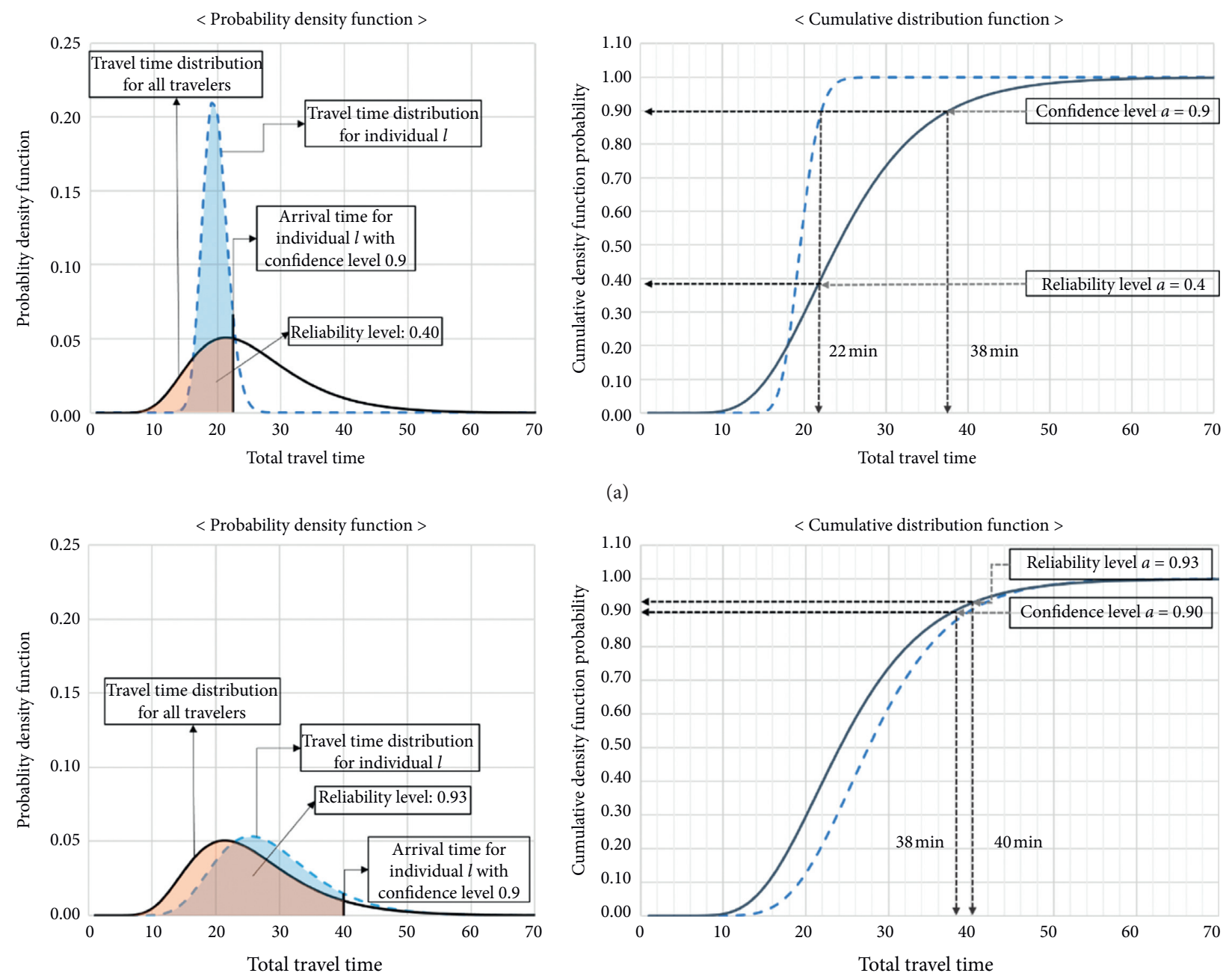

(b)

FiguRE 1: Distributional characteristics for risk preferences: (a) risk-seeking travellers; (b) risk-averse travellers.

important to determine the choice set by the different travel behaviour for individuals. Likewise, travellers consist of their own considered choice set of routes from information and experience. They set for their own choice set to choose the proper route of the travel. In comparison between the cognitive and modelling process, the constructing set of choice is crucial for interpreting route choice behaviour. The cognitive process and modelling process for route choice behaviour is shown in Figure 2:

4.2. Choice Set Generation Model. Since there are millions of alternatives in the network, it is time-consuming to analyse using all alternatives in the choice set, and travellers do not consider the enormous size of the choice set for travel. Determining the choice set in the route choice model is essential because it affects the prediction accuracy in modelling results [41]. Since it is important to know the routes considered in the network, this study employs actual travel data to derive the size of the consideration set and the individual choice set. Travellers identify the choice set for their travel by travelling the known routes and determining the alternative routes. The travellers recognise the optimal path between specific OD pairs according to their individual experiences, and the individuals choose the observed route from their optimal choice sets. Thus, all observed choice sets could be the optimal paths experienced by individuals for the OD pairs. Travellers repeat creating and determining a route from the set of choices by considering their specific situations.

The route searching algorithm is developed to generate a choice set for individuals using TTB and risk preference. This algorithm generates a set of considered paths using the CDF of travel times. A set of individual paths is determined according to the number of paths specified in advance. It is necessary to generate the choice set with an appropriate size to estimate the choice probability. There are experienced paths that could be used to determine the proper size of the choice set, making it possible to know the exact path for each traveller. Also, the single alternative chosen by a traveller is one of the experienced paths. Fiorenzo-Catalano [48] mentioned the importance of determining the choice set by 


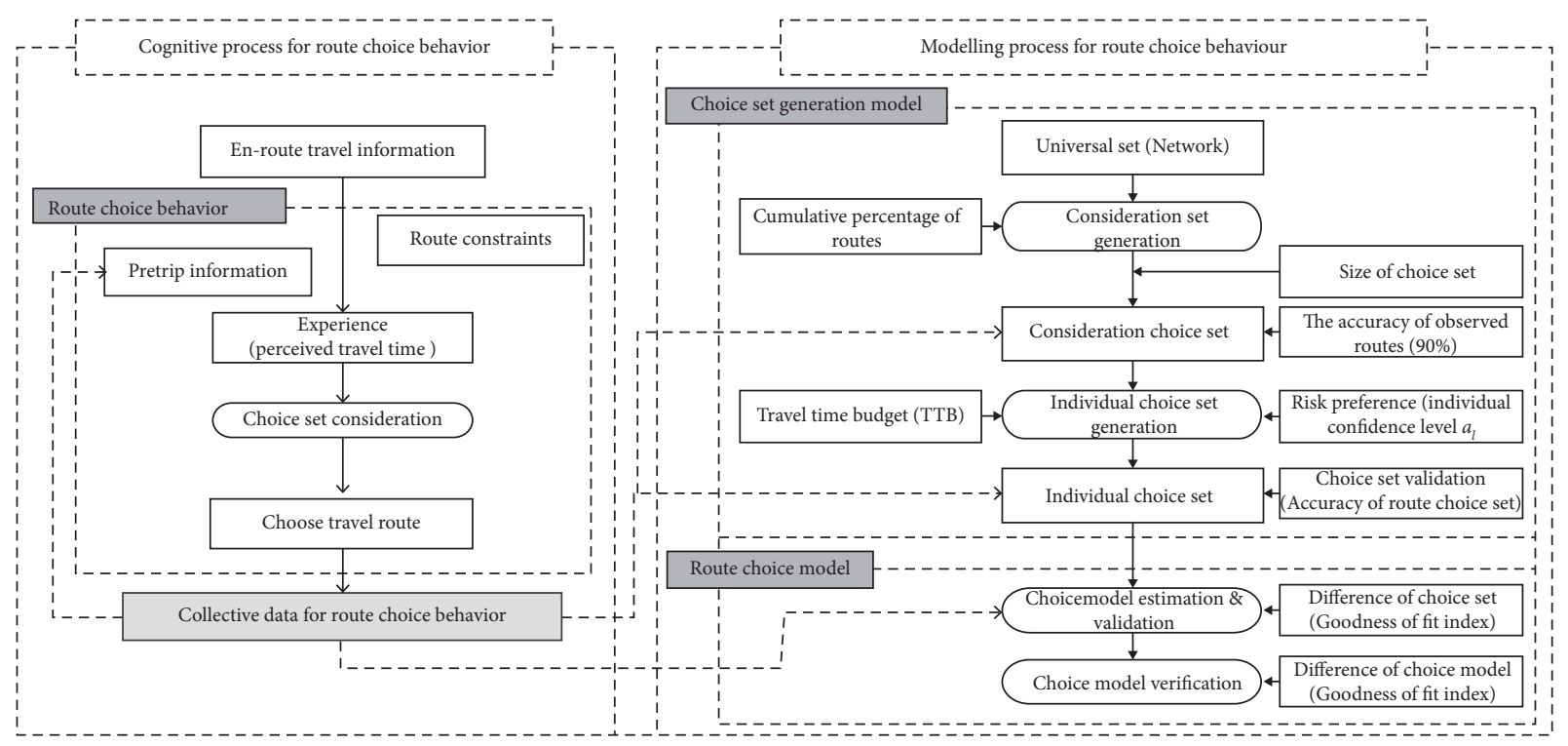

Figure 2: Modelling process for route choice behaviours.

considering the researchers' perspectives because there are differences between travellers' perspectives and researchers' perspectives [48]. Since the researchers do not know individual travellers' choice sets, some assumptions are required in the choice set generation model. Two sets identify the appropriate choice set in the route choice model, i.e., the consideration set and the individual choice set. The consideration set includes the paths that most travellers are likely to choose. Besides, individual choice sets have the proper size for individual travellers to make their route choices.

The $\mathrm{k}-\alpha$-reliable shortest path searching algorithm for generating an individual choice set is consisted of eight steps, as shown below. First, the observed travel time is extracted from the database for a specific OD pair. Next, confidence level, $\alpha$, is specified for the travel time reliability to achieve network performance with the value of 0.9 or more, as suggested in the previous study $[16,49]$. Then, it is necessary to calculate the travel time distribution in the network and the TTB to derive the reliability level, $\alpha_{l}$ $\left(\operatorname{TTB}_{T^{i j}}(\alpha)\right)$. Next, the travel time distribution is formed for each route TTB $\left(\mathrm{TTB}_{T_{k}^{i j}}(\alpha)\right)$. From this process, the reliability level, $\alpha_{l}$, is calculated according to the individual travel time distribution from the individual TTB $\left(\mathrm{TTB}_{T i j l}(\alpha)\right)$. Finally, the choice set for an individual is derived by calculating TTB according to reliability level, $\alpha_{l}$. The algorithm for searching choice set includes the procedure for probabilistic reliable path searching algorithm for $k$ - $\alpha$-reliable shortest paths (PRPSA-K $\alpha$ RSP). (Algorithm 1)

Figure 3 illustrates an example to understand the differences in travel time budgets. There are five alternatives to choose the proper route for the traveller. Some travellers choose the dominant route A among the alternatives due to the fastest mean travel time; on the contrary, the other travellers are willing to choose route $\mathrm{B}$ for the reason of reliable travel route. In addition, the travellers varied with the formations of different choice sets considering travel experiences with reliability level, $\alpha_{l}$.

The above algorithm is revised to generate the individual route choice set considering the observed route travels. Generating individual choice sets among various OD pairs should be repeated to model travellers' heterogeneity. Due to the different characteristics of individuals' observed choice set, it is possible to implement and derive the different perceived choice sets using the algorithm above. Even though the same travellers are on the other OD pairs, they would have different choice sets between the OD pairs due to their different experiences. The models are compared to the other models to evaluate each model's accuracy by developing the route choice model based on the choice set generation models.

4.3. Route Choice Model. There are various choice models to deal with the overlapping problems and cognitive process in the models. We explored which types of models are suitable for using data types and behavioural differences. There are overlapping problems in the route choice model, so it is necessary to propose an appropriate form. Also, a model that incorporated the heterogeneity of the travellers' route choice behaviour was suggested. There are various types of models, such as MNL [33], PSL and PSCL [35, 41], GNL [34], MMNL [45, 46], and MPSCL, based on the three kinds of choice set generation models. We compare those types of choice models considering data type and goodnessof-fit indexes.

Researchers tried to develop the improved model form in the overlapping problem. They developed the path-size logit model (PSL) for the improved MNL model, considering the degree of overlapping links. Bovy et al. proposed the improved path-size logit model [35]. Since there is no satisfactory derivation based on theoretical arguments, it is necessary to employ the correction terms. The model 
Step 1. Choosing the OD pair to observe the path $(i, j)$

Step 2. Setting the confidence level, $\alpha$, for the satisfaction of the level of service, i.e., $\alpha=0.9$

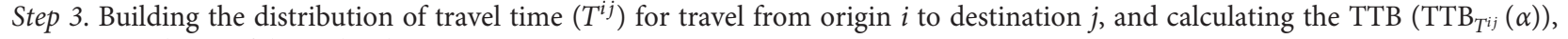
concerning the confidence level, $\alpha$

Step 4. Building the distribution of travel time for the $k^{\text {th }}$ path $\left(T_{k}^{i j}\right), \forall k \in(1, \ldots, U)$, for each observed travel from origin $i$ to destination $j$

Step 5. Building the distribution of travel time for individual $l\left(T^{i j l}\right)$ for each traveller from origin $i$ to destination $j$

Step 6. Evaluating the reliability level, $\alpha_{l}$, for each traveller $l, \alpha_{l}=\Phi_{T^{i j l}}\left(\ln \left(\mathrm{TTB}_{T^{i j}}(\alpha)-\mu^{i j l}\right) / \sigma^{i j l}\right)$, normal distribution $\Phi(x)=(1 / 2)[1+\operatorname{erf}(x / \sqrt{2})]$, where erf=error function

Step 7. Calculating the TTB $\left(\operatorname{TTB}_{T^{i j}}\left(\alpha_{l}\right)\right)$, for each path concerning the reliability level, $\alpha_{l}$

Step 8. Choosing the $K$ - $\alpha$-reliable shortest paths for individual $l$

Algorithm 1: PRPSA-K $\alpha$ RSP.
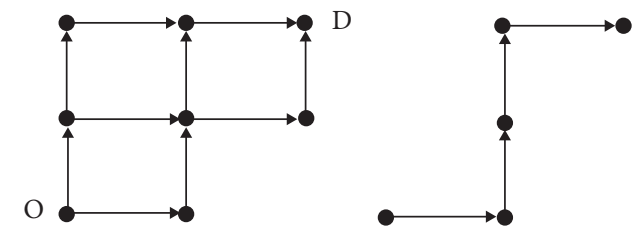

$<$ route $\mathrm{B}>$
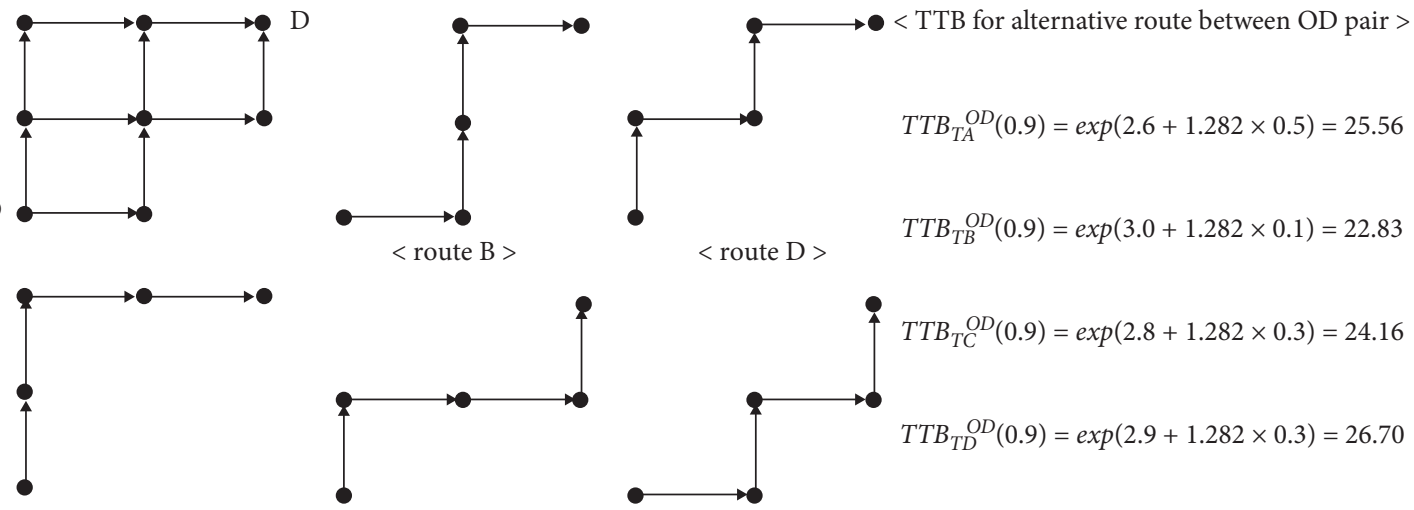

$<$ route $\mathrm{C}>$

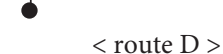

$\operatorname{TTB}_{T B}{ }_{T B}(0.9)=\exp (3.0+1.282 \times 0.1)=22.83$

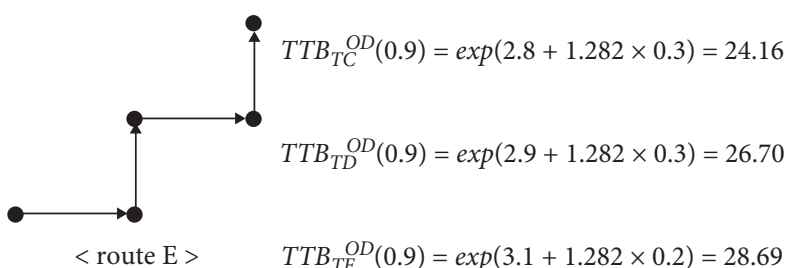

FIGURE 3: Route choice behaviour from perceived travel time.

considers the impact of choice set in the route choice model in equations (4) and (5):

$$
\begin{aligned}
P\left(i \mid A_{n}\right) & =\frac{e^{V_{i n}+\beta_{\mathrm{PSC}} * \mathrm{PSC}_{i n}}}{\sum_{j \in A_{n}} e^{V_{j n}+\beta_{\mathrm{PSC}} * \mathrm{PSC}_{j n}},} \\
\mathrm{PSC}_{i} & =-\sum_{a \in \Gamma_{i}}\left(\left(\frac{l_{a}}{L_{i}}\right) \ln \sum_{j \in A_{n}} \delta_{a j}\right),
\end{aligned}
$$

where $\mathbf{V}$ is the $A_{n}$ by $\mathrm{K}$ matrix of variables, $\beta$ is the column vector of $\mathrm{K}$ unknown parameters for variables, $\mathrm{PSC}_{i n}$ is the $A_{n}$ by one vector of path-size correction term, $L_{i}$ is the length of the travelled route of alternative $i, l_{a}$ is the overlapped link $a$, and $\delta_{a j}$ is the binary variable if the link $a$ exists in route $L_{i}$, 1 , otherwise 0 .

Moreover, researchers have proposed a mixed logit model to overcome the limitations of the logit model by adding error terms in the equation to account for the correlation among routes [39]. Since travellers' perceived routes are correlated, the error term is added to illustrate the relationship based on the topology of paths. The error term is divided into two parts in the model. One part represents correlation and heterogeneity, and the other part describes i.i.d (independently identically differentiated) extreme value. The equation of MPSCL is presented as

$$
\mathbf{P}_{n}(\mathbf{i})=\Lambda(i \mid \xi)=\frac{\exp \left(\mu\left(X_{\mathrm{in}} \beta+\mathrm{F}_{\mathrm{in}} \mathrm{T} \xi\right)+\ln \left(\mathrm{PSC}_{\mathrm{in}}\right)\right)}{\sum_{\mathrm{J} \in \mathrm{C}_{\mathrm{n}}} \exp \left(\mu\left(\mathrm{X}_{\mathrm{jn}} \beta+\mathrm{F}_{\mathrm{jn}} \mathrm{T} \xi\right)+\ln \left(\mathrm{PSC}_{\mathrm{jn}}\right)\right)}
$$

where $\mathbf{X}$ is $C_{n}$ by $K$ matrix of variables, $\beta$ is the column vector of $\mathrm{K}$ unknown parameters for variables, $\mathbf{F}_{\mathbf{i n}} \mathbf{T} \xi$ is $C_{n}$ by one vector of error terms, $\mathbf{F}$ is the $C_{n}$ by $M$ factor loading matrix, $\mathrm{T}$ is $M$ by $M$ lower triangular matrix of unknown parameters, $\zeta$ is $M$ by one vector of i.i.d standard normal variables as unobservable factors, $v$ is $M$ by $M$ lower triangular matrix of unknown parameters, and $\Gamma(k \mid \zeta)$ is the probability of chosen route $k$ with given $\zeta$.

\section{Revealed Preference Routing Data}

5.1. Data Descriptions. A case study was performed to apply the proposed methodology to solve the HK $\alpha$ RSP problem. The actual travelled data were used on the road network in the Daegu metropolitan area in South Korea. The actual path travel data were constructed by processing the information collected by the roadside equipment (RSE) installed on the intersections between arterial roads. Information of vehicular travel was collected using telecommunications between the RSE device installed on the road and the on-board unit (OBU) device installed in vehicles by a dedicated short-range communication (DSRC) device. 
The DSRC was a useful technique for collecting traffic information, such as the number of vehicles passing by a specific location. The data were more accurate than the GPS data used in previous research. However, since it collected point data, a conversion process was required to track the OBU ID of an individual vehicle observed from the RSE to convert the data into individual route data. The model included a process of generating routes to track an individual's chosen routes. It used the route data with the high frequency for a specific OD pair to model an individual's perceived travel time. From a brief analysis of the data, basic statistics and study area are shown in Table 2.

5.2. Data Processing and Missing Correction. Since the DSRC data was a type of point-based data observed at an intersection of the arterial roads, it was necessary to convert them into route data. The process for tracking the travellers with the same vehicle ID (OBU ID) was conducted to identify each route. The model was constructed based on methods of classifying and generating route data by tracking individual vehicles.

It was necessary to identify the individual vehicles to change from point data to route data. The observed-time variable was used to construct this process. If the observed times for individuals on RSE were arranged in order, it was possible to produce the individuals' route data. The link travel time was calculated while moving from node to node, and it included checking whether the path was configured using the link travel time. To generate the route travel time for specific OD pairs, it is necessary to produce the route travel data from point observation data. When the link travel time was excessive from a certain marginal value (divided by 10 minutes), it was divided into different travels [50]. We also scattered the plot using the observed travel time to separate the route travel, including about $98 \%$ of travels in 10 minutes. The route data process has presented the step by step to generate each travellers' route travel, sequentially listing the data observed at the point (see Figure 4(a)). However, it was impossible to confirm whether the link between the two nodes is connected or not. There were the following three types of missing data. (1) Missing data between nodes on an arterial road by straightway, (2) missing data between nodes for the type of road with the uninterrupted flow, and (3) observation of one node on two different observations. It was necessary to define the links between the nodes to ensure whether they were related links. If the produced route data were the case of missing data, it was necessary to identify the target nodes or links. With the missing correction method, the route data were connected with the other node. This process was performed using all of the missing data. The developed algorithm performed the missing correction procedures (see Figure 4(b)).

\section{Results}

6.1. Structure of Route Choice Model. The specified model has required the actual data to generate individual choice sets based on the distribution of perceived travel times. The individual choice set was a set of paths that incorporated the travellers' heterogeneity. The choice set generation model determines the individual choice sets based on the different travel experiences. The route choice model that incorporated the heterogeneous choice set generation model was used to compare the travel behaviours.

There were more than 30 thousands of possible OD pairs among nodes. It was necessary to choose the feasible data for analysis of route choice behaviour. Since some OD pairs were too close or far away to analyse the travel behaviours, available OD pairs were selected, having more than twenty thousand observed trips and proper distances within $5 \mathrm{~km}$ to $25 \mathrm{~km}$ between OD pairs. The 76 OD pairs were chosen for the analysis to describe the heterogeneous travel behaviours. From the observations, 40 thousands travellers having frequent observed trips were selected for the final analysis. As mentioned before, it was important to determine the appropriate set to be considered from the thousands of alternatives. A methodology was established for choosing the choice set to be considered using actual travel data. The consideration choice sets should include all of the possible choice sets for most of the travellers. According to the assumptions presented above, we determined the possible number of consideration set and the individual's number of the choice set (K) using the observed data. Since the use of all observed paths was against the assumption, the size of the consideration set was determined to 16 observed paths considering $90 \%$ of the coverage probability as consideration choice set. It is necessary to determine how many travelled paths were chosen in the choice set for individuals from the observed data. To determine the alternative $K$ for each individual, the $80 \%$ observed routes for each individual were calculated on average 3.12 routes except for observed at once, and the number of individual choices set was determined as four paths in the model.

The developed model used the actual travel data to analyse the route choice model. The NLOGIT 6.0 program, which is generally used for econometric analysis, was used to analyse the route choice model in this study. The MNL model was developed for estimating the parameters in the choice model with maximum likelihood estimation (MLE) methods. Generally, the more explanatory variables make a better goodness-of-fit index, but the correlated variables decrease the accuracy of parameter estimation. Even though there are many other kinds of variables from the raw data, it is necessary to analyse the correlation among variables to identify the effects of parameters appropriately. The explanatory variables were compared to whether the variables improve the goodness-of-fit or multicollinearity, and Pearson correlation analysis was employed to choose the appropriate variables. The model was developed to compare the relative size of variables between alternatives in the model without alternative specific constants (ASCs). It was necessary to retain the dummy variables to avoid biasedness [51]. Since travellers tended to consider more travel attributes than an immanent attribute of alternatives in route choice, the additional variables were needed instead of ASCs in the model. The variables were used to analyse the route 
Table 2: Data description and empirical study area (Daegu metropolitan area).

Division

\# of observed travellers

\# of OD pair

Mean of travelled route

Mean of link distance

Mean of OD trips

Value

About 0.6 million per month 31,152

About 30 million per month

1.25

6,015

\section{Unit}

Travellers

Pair

Trips

$\mathrm{Km}$

Trips

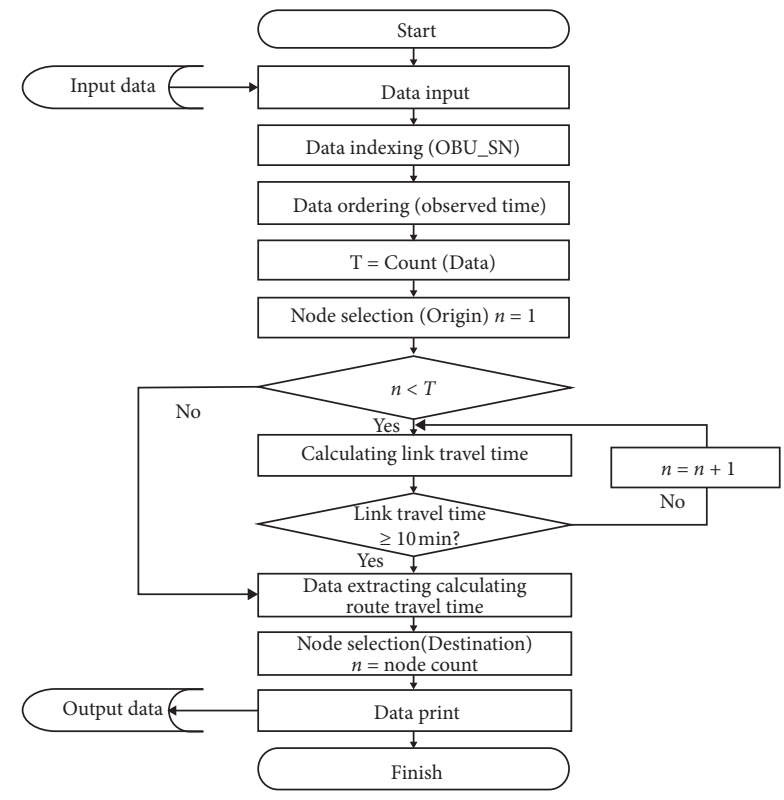

(a)

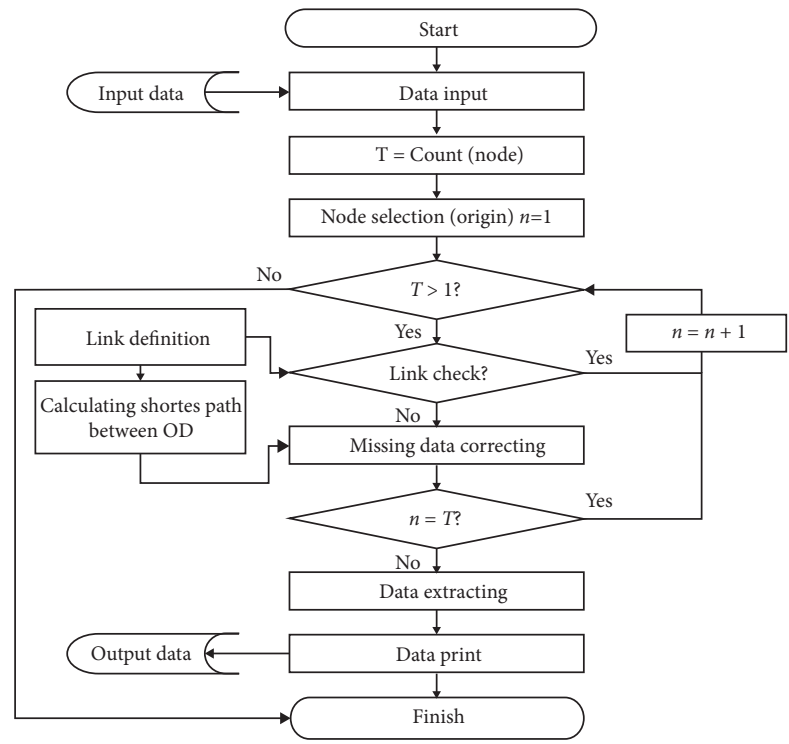

(b)

FIgURE 4: Data processing and correction: (a) algorithm for route data processing; (b) algorithm for the correction of missing data.

choice model using the DSRC data, i.e., travel time, buffer time, distance, ratio of uninterrupted flow road, tolls, and number of bridges. The final model was established with the several chosen variables of the following equation:

$$
\begin{aligned}
V_{k}= & \beta_{1} \mu_{k}^{i j}+\beta_{2} \mathrm{BT}_{k}^{i j}+\beta_{3} \mathrm{DIST}_{k}^{i j}+\beta_{4} \mathrm{UNINT}_{k}^{i j}+\beta_{5} \mathrm{TOLL}_{k}^{i j} \\
& +\beta_{6} \mathrm{BRIDGE}_{k}^{i j},
\end{aligned}
$$

where $V_{k}$ is the utility function for alternative $k, \beta_{i}$ are the parameters, $\mu_{k}^{i j}$ is the mean travel time for alternative $k$ from origin $i$ to destination $j, \mathrm{BT}_{k}^{i j}$ is the buffer travel time for alternative $k$ from origin $i$ to destination $j, \operatorname{DIST}_{k}^{i j}$ is the distance travelled for alternative $k$ from origin $i$ to destination $j, \mathrm{UNINT}_{k}^{i j}$ is the ratio of uninterrupted flow for alternative $k$ from origin $i$ to destination $j$, TOLL ${ }_{k}^{i j}$ is the toll for alternative $k$ from origin $i$ to destination $j$, and BRIDGE ${ }_{k}^{i j}$ is the number of bridges for alternative $k$ from origin $i$ to destination $j$.

6.2. Heterogeneous Route Choice Models. The model was determined by evaluating the data, modelling structure, and goodness-of-fit index among the various other models, i.e., MNL, PSL, PSCL, MMNL, and MPSCL. This research employed the MPSCL model reflecting the overlapping links and considering the traveller's heterogeneity. The MPSCL model is necessary to analyse the route choice behaviour considered the route overlapping, which has a significant impact on the model's estimation, and the model had a much improved $\rho^{2}$ compared to the other models. The result showed the route choice model based on the different choice set generation model. The results of the model comparison are presented in Table 3.

The proposed model provided the most precise prediction of a route's choice probability using choice set generation with traveller heterogeneity. Due to the coincidence of consideration set generation and path-size correction term, the model had better model fitness indexes. Consideration of identified choice set for travellers was adopted in the MPSCL model. The model had a better accuracy of prediction for route choice probability in $\mathrm{HK} \alpha \mathrm{RSP}$ model than the K $\alpha$ RSP and KSP model.

The estimated model parameters had the appropriate value in the model and drew the significance at $1 \%$ level for most models. The parameters represented the variables' variations; in other words, the variables had a different effect on the choice for individual travellers, which is modelled by the random parameters. The mean and standard deviation parameters of travel time affected the model in the MPSCL 
TABLE 3: Result of MPSCL model with truncated normal distribution.

\begin{tabular}{|c|c|c|c|}
\hline \multirow{2}{*}{\multicolumn{4}{|c|}{$\begin{array}{l}\text { Explanatory variables } \\
\text { Level of service (LOS) attribute variable }\end{array}$}} \\
\hline & & & \\
\hline $\begin{array}{ll}\text { Mean travel time }\left(\mu_{k}^{i j}\right) & \text { Constant } \\
\text { Buffer time }\left(\mathrm{BT}_{k}^{i j}\right) & \text { Standard deviation } \\
\text { Travel distance }\left(\mathrm{DIST}_{k}^{i j}\right) & \\
\end{array}$ & $\begin{array}{c}-0.3121^{* * *} \\
1.3852^{* * *} \\
-0.3129^{* * *} \\
-0.5840^{* * *}\end{array}$ & $\begin{array}{c}-0.0404^{* * *} \\
0.3073^{* * *} \\
-0.2300^{* * *} \\
-1.1117^{* * *}\end{array}$ & $\begin{array}{c}-0.0343^{* * *} \\
0.2865^{* * *} \\
-0.4009^{* * *} \\
-0.9177^{* * *}\end{array}$ \\
\hline $\begin{array}{l}\text { Network attribute variable } \\
\text { The ratio of uninterrupted flow road } \text { (UNINT }_{k}^{i j} \text { ) } \\
\text { Toll fare (TOLL }{ }_{k}^{i j} \text { ) (100won) } \\
\text { Number of bridge (BRIDGE }{ }_{k}^{i j} \text { ) } \\
\text { Path-size correction (PSC) }\end{array}$ & $\begin{array}{l}4.5800^{* * *} \\
-0.0959^{* * *} \\
-1.1636^{* * *} \\
-4.0237^{* * *}\end{array}$ & $\begin{array}{l}2.4270^{* * *} \\
- \\
-0.9013^{* * *} \\
-3.5107^{* * *}\end{array}$ & $\begin{array}{c}- \\
-0.0454^{* * *} \\
-0.0508^{* * *} \\
-1.7035^{* * *}\end{array}$ \\
\hline $\begin{array}{l}\text { Goodness of fit } \\
\text { Observations } \\
\# \text { of parameters } \\
\operatorname{LL}(0) \\
\operatorname{LL}(\beta) \\
\rho^{2} \\
\bar{\rho}^{2}\end{array}$ & $\begin{array}{c}40,000 \\
8 \\
-55,451.8 \\
-35,558.1 \\
0.3588 \\
0.3586\end{array}$ & $\begin{array}{l}40,000 \\
8 \\
-55,451.8 \\
-36,551.9 \\
0.3408 \\
0.3407\end{array}$ & $\begin{array}{c}40,000 \\
8 \\
-55,451.8 \\
-44,550.1 \\
0.1966 \\
0.1964\end{array}$ \\
\hline
\end{tabular}

${ }^{*}$ is $10 \%$ significance level, ${ }^{* *}$ is $5 \%$ significance level, ${ }^{* * *}$ is $1 \%$ significance level.

model, which means that travel time makes the differences in choice probability with traveller heterogeneity. The random parameters positively affected the log-likelihood estimation compared to basic models to improve parameters' accuracy. All parameters of the models had the appropriate values and were significant at $1 \%$. From the $\mathrm{HK} \alpha \mathrm{RSP}$ model result, there was the effect of the level of service and attribute network variables in the route choice model. Travellers considered the variation of mean travel time $\left(\beta_{1}\right.$ constant: $-0.3121 /$ standard deviation: 1.3852 ) by the heterogeneous choice behaviour. Travellers had the tendency not to increase the mean travel time, but they also were sensitive to the variation of travel time for the travel. The model is more sensitive to travel time reliability (BT, $\left.\beta_{2}:-0.3129\right)$ than average travel time $\left(\beta_{1}:-0.3121\right)$. The ratio of uninterrupted flow road $\left(\beta_{4}: 4.5800\right)$ had a significant positive effect on route choice behaviour due to the convenience of driving. They tended to choose the routes having many ratios of the uninterrupted travel route. Also, travellers did not want to choose the route with the bridges $\left(\beta_{6}:-1.1636\right)$, and it seemed to make congestion on the bridges.

There was an impact on the level of service attribute variables in the route choice model. The use of buffer time derived the better goodness of fit than the standard deviation of travel time for travel time reliability. The model had more sensitive to the travel time reliability (buffer time; BT) than average travel time $\left(\mu_{k}^{i j}\right)$. Less distance made the better model fit than the mean of travel time in route choice. Furthermore, there was an impact of additional network attribute variables in the route choice model. The higher ratio of uninterrupted flow revealed a higher choice probability in the model. There was a tendency for less preference to use of toll road for travel in the urban area. Travellers tended to avoid crossing the bridge in the model due to traffic congestion. Reflecting the traveller heterogeneity in the mixed logit model made the accuracy of estimations. This was due to the consistency of the structure for a choice set generation model and route choice model. Also, we evaluated the best fit for the MPSCL model with $\mathrm{HK} \alpha \mathrm{RSP}$ choice set generation model. The model had better model fitness indexes which resulted from the coincidence of consideration set generation and path-size correction term.

Many studies have recently been conducted to provide a new concept of transportation services such as smart mobility, mobility-as-a-service (MaaS), and an autonomous vehicle. These studies focused on identifying individual preferences and providing more convenient service by combining various travel modes suitable for those preferences. From this perspective, analysing route choice behaviour based on individual travel experience would be an important process in introducing new transportation services. The results derived through this study were judged to establish a more efficient transportation operation strategy by providing information on the reliable route for an individuals' preference. The provision of transportation services should provide faster information from individuals' experiences, and such information makes the entire system operate efficiently.

6.3. Model Validation. We validated the prediction accuracy for the route choice probability using the estimated parameters. There are differences according to the distance between OD pairs, and it is necessary to divide with the three categories based on the distance (short/medium/long distance). The prediction results were calculated by the observed travel attributes for each OD pair considering types of 
Short distance $(0 \sim 5 \mathrm{~km})$

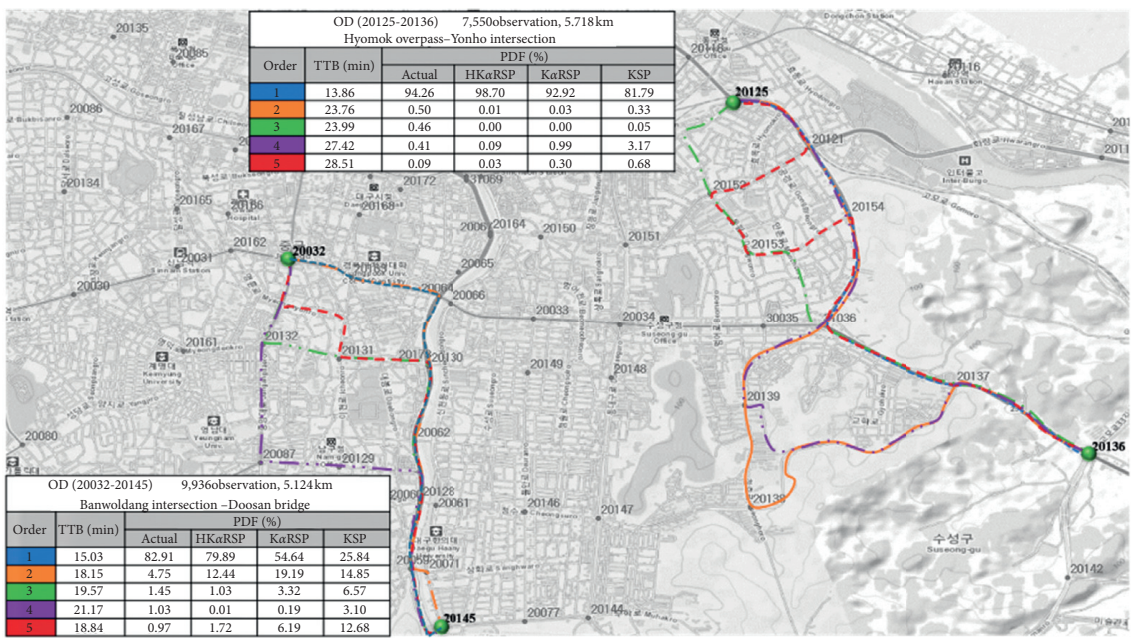

(a)

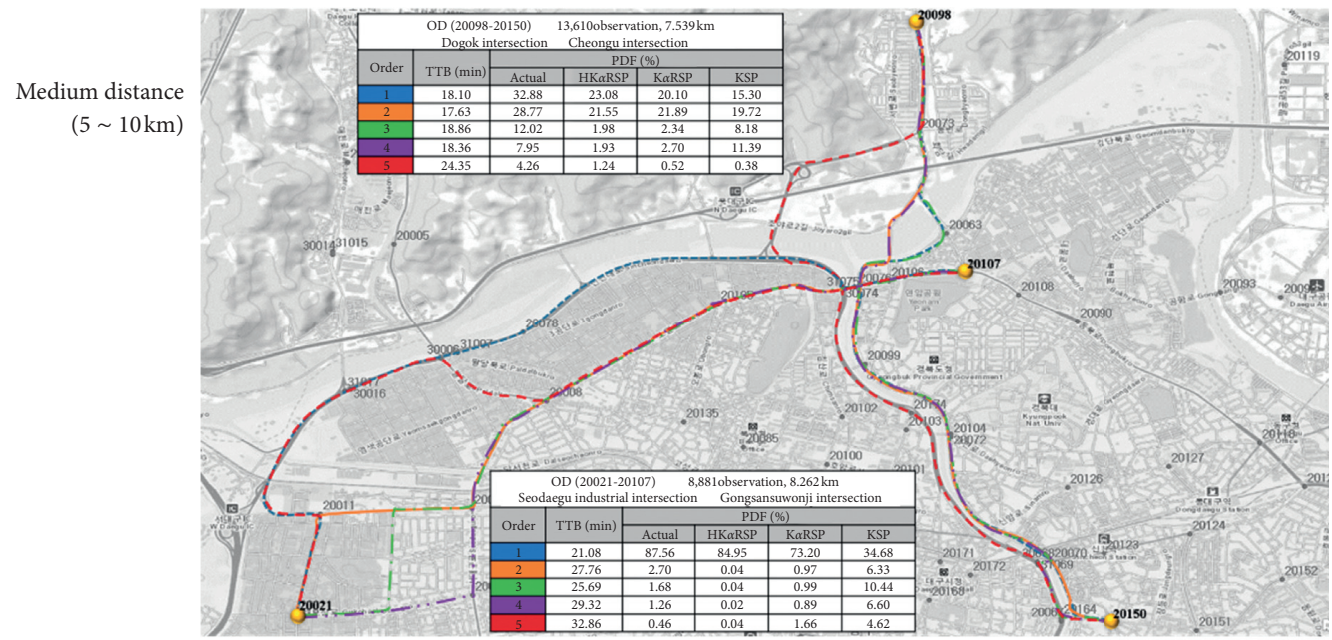

(b)

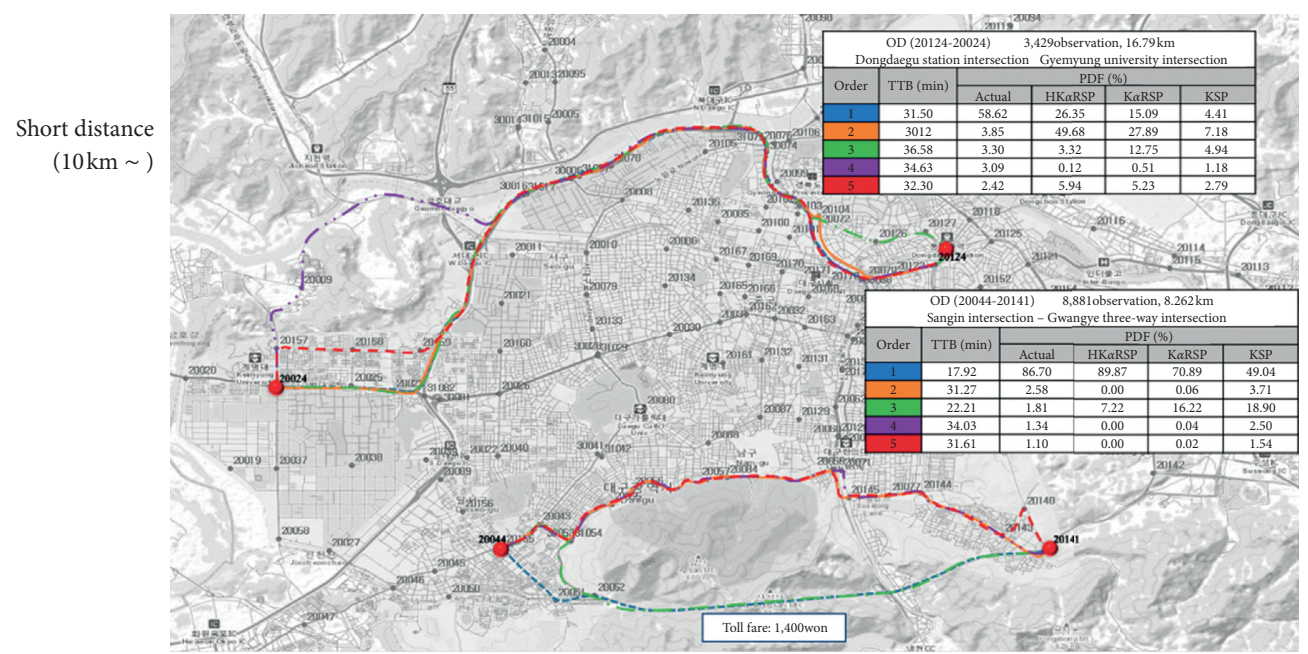

(c)

Figure 5: Model validation considering travel distance. 
choice set generation methods. The validation results are shown in Figure 5.

\section{Conclusion}

In this study, the distributional characteristics were employed to model the uncertainty concerning the travel time for individual travellers. We used the concept of TTB and the probability that travellers would arrive at their destinations on time. The definition of risk preference was introduced according to the difference between the TTB considered by individual travellers and the TTB presented in the network. There was a process for generating an individual choice set based on the accumulated experience of individuals. The process of route choice was performed to consider a different choice set for each traveller. The reliability level, $\alpha_{l}$, generated a path set by the cumulative travel time distribution for each path. We constructed a model for generating the choice set for individual travellers to incorporate the traveller's heterogeneity. The results obtained from actual path travel data showed that most travellers might consider the dominant path and select alternative paths similar to it if one dominant path exists. Also, travellers chose reliable paths to ensure ontime arrivals by the generated choice set.

The travellers were more sensitive to travel distance than travel time in the level of service attributes. The coefficients of travel time were in the range from -0.3121 to 0.0077 , and the coefficients of travel distance were in the range from -1.1117 to -0.5840 in the level of service attributes. The travellers tended to have preferences for the use of uninterrupted flow and bridges, and they preferred not to use toll roads. The coefficients of the ratio of uninterrupted flow were in the range from -0.1099 to 4.7544 , the estimation result of toll roads was in the range from -0.0959 to -0.0342 , and the parameters of bridges were in the range from -1.1636 to -0.0508 . The model had a better accuracy of prediction for route choice probability in the HK $\alpha$ RSP model than the K $\alpha$ RSP and KSP models. We derived better prediction according to the different travel distances. The results are applicable to transportation planning and traffic management by clarifying the choice set considered in the existing network. Moreover, it was possible to establish a strategy for providing route information using individuals' behavioural characteristics concerning transportation operation. Depending on the individual's risk preference, a different set of paths was considered, and a set of paths was established to provide information that is tailored to the individual reliability level, $\alpha_{l}$. This study contributes to increasing the efficiency of traffic operation and planning according to individuals' route attributes.

There is further research from the additional improvements in modelling. The choice set generation model derives the appropriate number of sets as a necessary process for constructing the route choice model. It is necessary to compute travel time distribution following the time-dependent model to compare the differences in the choice sets. Also, the methodology for estimating the route travel time can be developed based on the difference between an individual's actual travel time on a given route and the estimated route travel time from the link travel time distribution. Finally, this research can extend the stochastic user equilibrium model according to travellers' risk preferences using the route choice model, such as the fuzzy traffic assignment model.

\section{Data Availability}

The data used in this research were provided by the Trlab research programme conducted at the Seoul National University, Seoul, Republic of Korea. The data used to support the findings of the study are available from the corresponding author upon request.

\section{Conflicts of Interest}

The authors declare that there are no conflicts of interest regarding the publication of this paper.

\section{Acknowledgments}

This research was supported by Basic Science Research Program through the National Research Foundation of Korea (NRF) funded by the Ministry of Science and ICT (2020R1F1A1061802). The authors express their gratitude for the support.

\section{References}

[1] R. B. Dial, "A probabilistic multipath traffic assignment model which obviates path enumeration," Transportation Research, vol. 5, no. 2, pp. 83-111, 1971.

[2] J. Y. Yen, "Finding the $K$ Shortest loopless paths in a network," Management Science, vol. 17, no. 11, pp. 712-716, 1981.

[3] C. Fisk, "Some developments in equilibrium traffic assignment," Transportation Research Part B: Methodological, vol. 14 , no. 3, pp. 243-255, 1980.

[4] M. Chen and A. S. Alfa, "A network design algorithm using a stochastic incremental traffic assignment approach," Transportation Science, vol. 25, no. 3, pp. 215-224, 1991.

[5] N. Schuessler and K. Axhausen, "Processing raw data from global positioning systems without additional information," Journal of the Transportation Research Board, vol. 2105, pp. 28-36, 2009.

[6] X. Pan Zuo and K. Liu, "Parameter calibration in cumulative prospect theory for travellers' route choice behaviour," in Proceedings of the COTA International Conference of Transportation Professionals, pp. 2696-2708, Beijing, China, July 2015.

[7] P. H. L. Bovy, "On modelling route choice sets in transportation networks: a synthesis," Transport Reviews, vol. 29, no. 1, pp. 43-68, 2009.

[8] W. H. K. Lam, S. C. Wong, and H. K. Lo, Transportation and Traffic Theory 2009: Golden Jubilee, Springer, Berlin, Germany, 2009.

[9] C. Sun, L. Cheng, S. Zhu, F. Han, and Z. Chu, "Multi-criteria user equilibrium model considering travel time, travel time reliability and distance," Transportation Research Part D: Transport and Environment, vol. 66, pp. 3-12, 2019.

[10] K. K. Srinivasan, A. A. Prakash, and R. Seshadri, "Finding most reliable paths on networks with correlated and shifted log-normal travel times," Transportation Research Part B: Methodological, vol. 66, pp. 110-128, 2014. 
[11] H. Frank, "Shortest paths in probabilistic graphs," Operations Research, vol. 17, no. 4, pp. 583-599, 1969.

[12] Y. Nie and Y. Fan, "Arriving-on-time problem: discrete algorithm that ensures convergence, transportation research record," Journal of the Transportation Research Board, vol. 1964, pp. 193-200, 2006.

[13] B. Y. Chen, W. H. K. Lam, A. Sumalee et al., "Finding reliable shortest paths in road networks under uncertainty," Networks and Spatial Economics, vol. 13, no. 2, pp. 123-148, 2013.

[14] Y. M. Nie and X. Wu, "Reliable a priori shortest path problem with limited spatial and temporal dependencies," in Transportation and Traffic Theory 2009: Golden Jubilee, pp. 169-195, Springer, Berlin, Germany, 2009.

[15] B. Y. Chen, W. H. K. Lam, A. Sumalee, and Z.-I. Li, "Reliable shortest path finding in stochastic networks with spatial correlated link travel times," International Journal of Geographical Information Science, vol. 26, no. 2, pp. 365-386, 2012.

[16] B. Y. Chen, Q. Li, and W. H. K. Lam, "Finding the K Reliable shortest paths under travel time uncertainty," Transportation Research Part B: Methodological, vol. 94, pp. 189-203, 2016.

[17] A. Chen and Z. Zhou, "The $\alpha$-reliable mean-excess traffic equilibrium model with stochastic travel times," Transportation Research Part B: Methodological, vol. 44, no. 4, pp. 493-513, 2010.

[18] A. Chen, Z. Zhou, and W. H. K. Lam, "Modeling stochastic perception error in the mean-excess traffic equilibrium model," Transportation Research Part B: Methodological, vol. 45, no. 10, pp. 1619-1640, 2011.

[19] H. K. Lo and Y.-K. Tung, "Network with degradable links: capacity analysis and design," Transportation Research Part B: Methodological, vol. 37, no. 4, pp. 345-363, 2003.

[20] H. K. Lo, X. W. Luo, and B. W. Y. Siu, “Degradable transport network: travel time budget of travellers with heterogeneous risk aversion," Transportation Research Part B: Methodological, vol. 40, no. 9, pp. 792-806, 2016.

[21] X. Wu and Y. Nie, "Implementation issues for the reliable a priori shortest path problem, transportation research record," Journal of the Transportation Research Board, vol. 2091, pp. 51-60, 2009.

[22] X. Wu, "Study on mean-standard deviation shortest path problem in stochastic and time-dependent networks: a stochastic dominance based approach," Transportation Research Part B: Methodological, vol. 80, pp. 275-290, 2015.

[23] A. Chen and Z. Ji, "Path finding under uncertainty," Journal of Advanced Transportation, vol. 39, no. 1, pp. 19-37, 2005.

[24] H. Ramazani, Y. Shafahi, and S. E. Seyedabrishami, "A fuzzy traffic assignment algorithm based on driver perceived travel time of network links," Scientia Iranica, vol. 18, no. 2, pp. 190-197, 2011.

[25] G. E. Cantarella and V. Fedele, "Fuzzy utility theory for analysing discrete choice behaviour," in Proceedings of the Fourth International Symposium on Uncertainty Modeling and Analysis, ISUMA 2003, pp. 148-154, College Park, MD, USA, September 2003.

[26] M. Ridwan, "Fuzzy preference based traffic assignment problem," Transportation Research Part C: Emerging Technologies, vol. 12, no. 3-4, pp. 209-233, 2004.

[27] T. Lotan, "Effects of familiarity on route choice behavior in the presence of information," Transportation Research Part C: Emerging Technologies, vol. 5, no. 3-4, pp. 225-243, 1997.

[28] M. Miralinaghi, Y. Lou, Y. T. Hsu, R. Shabanpour, and Y. Shafahi, "Multiclass fuzzy user equilibrium with endogenous membership functions and risk taking behaviors,"
Journal of Advanced Transportation, vol. 50, no. 8, pp. 1716-1734, 2016.

[29] M. Miralinaghi, Y. Shafahi, and R. S. Anbarani, "A fuzzy network assignment model based on user equilibrium condition," Scientia Iranica A, vol. 22, no. 6, pp. 2012-2023, 2015.

[30] D. McFadden, Conditional Logit Analysis of Qualitative Choice Behaviour, University of California at Berkeley, Berkeley, CL, USA, 1973.

[31] Y. Sheffi and W. B. Powell, "An algorithm for the equilibrium assignment problem with random link times," Networks, vol. 12, no. 2, pp. 191-207, 1982.

[32] E. Cascetta, F. Russo, F. A. Viola, and A. Vitetta, "A model of route perception in urban road networks," Transportation Research Part B: Methodological, vol. 36, no. 7, pp. 577-592, 2002.

[33] S. Bekhor, M. E. Ben-Akiva, and M. S. Ramming, "Evaluation of choice set generation algorithms for route choice models," Annals of Operations Research, vol. 144, no. 1, pp. 235-247, 2006.

[34] C. Prato and S. Bekhor, "Applying branch-and-bound technique to route choice set generation, Transportation Research Record," Journal of the Transportation Research Board, vol. 1985, pp. 19-28, 2006.

[35] P. Bovy, S. Bekhor, and C. Prato, "The factor of revisited path size: alternative derivation," Journal of the Transportation Research Board, vol. 2076, pp. 132-140, 2008.

[36] E. Cascetta, A. Papola, F. Russo et al., "Implicit availability/ perception logit models for route choice in transportation networks," World Transport Research: Selected Proceedings of the 8th World Conference on Transport Research World Conference on Transport Research Society, vol. 3, 1999.

[37] M. E. Ben-Akiva and J. L. Bowman, Activity Based Travel Demand Model Systems: Equilibrium and Advanced Transportation Modelling, pp. 27-46, Springer, Berlin, Germany, 1998.

[38] E. Frejinger, M. Bierlaire, and M. Ben-Akiva, "Sampling of alternatives for route choice modeling," Transportation Research Part B: Methodological, vol. 43, no. 10, pp. 984-994, 2009.

[39] D. Li, T. Miwa, T. Morikawa, and P. Liu, "Incorporating observed and unobserved heterogeneity in route choice analysis with sampled choice sets," Transportation Research Part C: Emerging Technologies, vol. 67, pp. 31-46, 2016.

[40] F. S. Koppelman and C.-H. Wen, "The paired combinatorial logit model: properties, estimation and application," Transportation Research Part B: Methodological, vol. 34, no. 2, pp. 75-89, 2000.

[41] M. Bliemer and P. Bovy, "Impact of route choice set on route choice probabilities," Journal of the Transportation Research Board, vol. 2076, pp. 10-19, 2008.

[42] P. Vovsha and S. Bekhor, "Link-nested logit model of route choice: overcoming route overlapping problem," Transportation Research Record: Journal of the Transportation Research Board, vol. 1645, no. 1, pp. 133-142, 1998.

[43] S. Bekhor and J. N. Prashker, "Stochastic user equilibrium formulation for generalized nested logit model," Transportation Research Record: Journal of the Transportation Research Board, vol. 1752, no. 1, pp. 84-90, 2001.

[44] C.-H. Wen and F. S. Koppelman, "The generalized nested logit model," Transportation Research Part B: Methodological, vol. 35, no. 7, pp. 627-641, 2001.

[45] M. Bierlaire and E. Frejinger, "Route choice models with subpath components," in Proceedings of the Swiss 
Transportation Research Conference, Ascona, Switzerland, August 2005.

[46] S. Hess and J. M. Rose, "Allowing for intra-respondent variations in coefficients estimated on repeated choice data," Transportation Research Part B: Methodological, vol. 43, no. 6, pp. 708-719, 2009.

[47] X. Xu, A. Chen, L. Cheng et al., "Modeling distribution tail in network performance assessment: a mean-excess total travel time risk measure and analytical estimation method," Transportation Research Part B: Methodological, vol. 66, pp. 32-49, 2014.

[48] M. S. Fiorenzo-Catalano, Choice Set Generation in MultiModal Transportation Networks, Netherlands TRAIL Research School, Delft, Netherlands, 2007.

[49] X. Wu and Y. Nie, "Modeling heterogeneous risk-taking behavior in route choice: a stochastic dominance approach," Transportation Research Part A: Policy and Practice, vol. 45, no. 9, pp. 896-915, 2011.

[50] X. Zhan, S. Hasan, S. V. Ukkusuri, and C. Kamga, "Urban link travel time estimation using large-scale taxi data with partial information," Transportation Research Part C: Emerging Technologies, vol. 33, pp. 37-49, 2013.

[51] M. S. Ramming, Network Knowledge and Route Choice, Massachusetts Institute of Technology, Cambridge, MA, USA, 2001.

[52] E. Castillo, J. M. Menendez, P. Jimenez, and A. Rivas, "Closed form expressions for choice probabilities in the Weibull case," Transportation Research Part B: Methodological, vol. 42, no. 4, pp. 373-380, 2008.

[53] S. Kitthamkesorn and A. Chen, "A path-size weibit stochastic user equilibrium model," Transportation Research Part B: Methodological, vol. 57, pp. 378-397, 2013.

[54] H. Alizadeh, B. Farooq, C. Morency, and N. Saunier, "On the role of bridges as anchor points in route choice modeling," Transportation, vol. 45, no. 5, pp. 1181-1206, 2017.

[55] J.-H. Lee, S.-H. Cho, D.-K. Kim, and C. Lee, "Valuation of travel time reliability accommodating heterogeneity of route choice behaviors," Transportation Research Record: Journal of the Transportation Research Board, vol. 2526, pp. 86-93, 2016. 